\title{
Management of gastrointestinal stromal tumours in the Imatinib era: a surgeon's perspective Ravindra S Date*†, Nicholas A Stylianides ${ }^{\dagger}$, Kishore G Pursnani, Jeremy B Ward and Muntzer M Mughal
}

Address: Department of Gastrointestinal Surgery, Lancashire Teaching Hospital NHS, Foundation Trust, Preston Road, Chorley, Lancashire, PR7 $1 \mathrm{PP}, \mathrm{UK}$

Email: Ravindra S Date* - ravidate@hotmail.com; Nicholas A Stylianides - nickstylianides@hotmail.com;

Kishore G Pursnani - kish.pursnani@lthtr.nhs.uk; Jeremy B Ward - jeremy.ward@lthtr.nhs.uk; Muntzer M Mughal - muntzer@btinternet.com

* Corresponding author †Equal contributors

Published: 18 July 2008

World Journal of Surgical Oncology 2008, 6:77 doi:10.1 186/1477-78/9-6-77

This article is available from: http://www.wjso.com/content/6/1/77

(c) 2008 Date et al; licensee BioMed Central Ltd.

This is an Open Access article distributed under the terms of the Creative Commons Attribution License (http://creativecommons.org/licenses/by/2.0), which permits unrestricted use, distribution, and reproduction in any medium, provided the original work is properly cited.
Received: 9 March 2008

Accepted: 18 July 2008

\begin{abstract}
Background: Surgical resection has remained the mainstay of treatment of GIST with a 5-yearsurvival of 28-35\%. Tyrosine kinase inhibitor (Imatinib) has revolutionised the treatment of these tumours. The current research is directed towards expanding the role of this drug in the treatment of GIST. We present our experience of managing GIST in this institute.
\end{abstract}

Methods: This is a case note study of patients identified from a prospectively kept database from January 2000 to August 2007.

Results: 16 patients were diagnosed with GIST. The median age was 66 years (range 46 to 82 ) and the male to female ratio was 9:7. Eleven patients underwent surgery, 9 of which had R0 resection (2 laparoscopic, I converted to open), one had an open biopsy and one had a debulking procedure. 3 patients were inoperable and 2 were found to be unfit for surgery. Five patients received Imatinib ( 2 postoperatively). The risk assessment based on morphological criteria showed that 4 patients had low, 4 had intermediate and 8 had high malignant potential. The median follow up was for 12 months (range 3-72); 2 patients died of unrelated causes at 6 and 9 months after diagnosis.

Conclusion: Most GISTs can be managed effectively using existing protocols. However currently there is no evidence based guidance available on the management of GIST in the following situations-role of debulking surgery, the follow up of benign tumours not requiring surgical resection and role of laparoscopic surgery. Further research is needed to answer these questions.

\section{Background}

Gastrointestinal stromal tumours (GIST) represent a subgroup of mesenchymal tumours, which were traditionally known as leiomyomas or leiomyosarcomas and have traditionally been treated by surgery. The results of a simple surgical resection with clear margins were comparable to those of a radical resection [1]. Therefore until recently simple resectional surgery remained the mainstay of treatment with 5-year-survival rates of $28-35 \%[2,3]$ for R0 resections. Introduction of Imatinib mesylate (tyrosine kinase inhibitor) for the treatment of GIST at the beginning of this century has improved outcomes in metastatic and unresectable tumours. Demetri et al have shown that Imatinib is useful in the treatment of unresectable or met- 
astatic GIST with more than half the patients showing a sustained response [4]. Verweij et al have shown that a dose of $400 \mathrm{mg}$ twice a day achieves significantly longer progression-free survival [5]. Two small retrospective studies have suggested that neoadjuvant Imatinib therapy may have a role in advanced GIST and have suggested a prospective evaluation [6,7]. Most of the current research is directed towards establishing the role of Imatinib as an adjuvant to surgery [8-11]. Management of small GIST is mainly in the form of watchful waiting as suggested in the consensus statement by ESMO[12], however there is no strong evidence to support this statement.

In spite of these developments the role of surgery itself has remained unchanged. We present our experience of 16 cases managed in this institute since introduction of Imatinib.

\section{Methods}

A case note study of all the patients diagnosed with GIST from January 2000 to August 2007 was carried out. Cases were identified from a prospectively kept database in the unit.

\section{Results}

16 patients were diagnosed with GIST during the study period. The demographics, presentation, histology, management and follow up of these patients are summarised in Table 1. Eleven patients underwent surgery, 9 of which had $\mathrm{R} 0$ resection. Two of these patients had laparoscopic wedge excision and in one laparoscopic operation had to be converted to open to ensure R0 resection. One patient had an open biopsy to confirm the diagnosis before commencing Imatinib. The median follow up was for 12 months (range 3-72). Two patients died of unrelated causes at 6 and 9 months after the diagnosis.

Patient 6 was operated by Gynaecologist for fibroids and intraoperatively surgeons were called to remove a large irregular mass adherent to the greater curvature of the stomach and infiltrating the omentum. There was no evidence of peritoneal or liver metastasis. The mass was removed completely which proved to be GIST on histology with possible extra-gastrointestinal or gastric in origin.

Patients 9 and 13 had GIST in the oesophagus and the second part of the duodenum respectively. Due to their asso-

Table I: Summary of patients with GIST

\begin{tabular}{|c|c|c|c|c|c|c|c|c|c|c|}
\hline Patient & $\begin{array}{l}\text { Age, } \\
\text { Gender }\end{array}$ & Site & Presentation & $\begin{array}{l}\text { Maximum } \\
\text { diameter } \\
(\mathrm{mm})\end{array}$ & $\begin{array}{l}\text { CDII7 \& } \\
\text { CD34 }\end{array}$ & $\begin{array}{l}\text { Mitosis per } \\
\text { HPF }\end{array}$ & Operation & Imatinib & $\begin{array}{l}\text { Follow up } \\
\text { (months) }\end{array}$ & Risk \\
\hline I & $66, F$ & Stomach & Mass & 70 & Positive & $10 / 50$ & $\begin{array}{l}\text { Wedge } \\
\text { resection }\end{array}$ & No & $5, S D$ & High \\
\hline 2 & $82, M$ & stomach & Gl bleed & 60 & Positive & $2 / 50$ & $\begin{array}{l}\text { Wedge } \\
\text { resection }\end{array}$ & No & $12, S D$ & Inter \\
\hline 3 & $60, M$ & Stomach & Gl bleed & 75 & Positive & $2 / 50$ & $\begin{array}{l}\text { Lap to open } \\
\text { Wedge } \\
\text { resection }\end{array}$ & No & $12, S D$ & Inter \\
\hline 4 & $72, M$ & Stomach & $\begin{array}{l}\text { Pain and } \\
\text { distension }\end{array}$ & 110 & Positive & $300 / 50$ & Debulking & Yes & $22, S D$ & High \\
\hline 5 & $5 I, M$ & Stomach & Mass & 14.5 & Positive & None seen & Inoperable* & Yes & $3, \mathrm{PD}$ & High \\
\hline 6 & $61, F$ & $\begin{array}{l}\text { ?Stomach/?extra- } \\
\text { gasttrointestinal }\end{array}$ & $\begin{array}{l}\text { Mass and } \\
\text { distension }\end{array}$ & 260 & Positive & $8 / 50$ & $\begin{array}{l}\text { Excision and } \\
\text { total } \\
\text { hysterectomy }\end{array}$ & Yes \# & $45, S D$ & High \\
\hline 7 & $72, M$ & Stomach & Mass & 90 & Positive & $17 / 50$ & Inoperable*** & Yes & 6, Died of MI & High \\
\hline 8 & $68, F$ & Stomach & Gl bleed & 70 & Positive & $4 / 50$ & $\begin{array}{l}\text { Lap. wedge } \\
\text { resection }\end{array}$ & No & $24, S D$ & Inter \\
\hline 9 & $70, F$ & Oesophagus & Dysphagia & 20 & N/A & $N / A$ & Not fit & No & $29, S D$ & $\mathrm{~N} / \mathrm{A}$ \\
\hline 10 & $46, F$ & Stomach & GI bleed & 70 & Positive & $10 / 50$ & $\begin{array}{l}\text { Distal } \\
\text { gastrectomy }\end{array}$ & No & $3<\mathrm{SD}$ & High \\
\hline II & $77, \mathrm{~F}$ & Stomach & Gl bleed & 80 & Positive & $34 / 50$ & $\begin{array}{l}\text { Distal } \\
\text { gastrectomy }\end{array}$ & No & 9, Died & High \\
\hline 12 & $47, M$ & Stomach & Gl bleed & 50 & Not done & Not done & $\begin{array}{l}\text { Wedge } \\
\text { resection }\end{array}$ & No & $72, S D$ & N/A \\
\hline 13 & $60, M$ & Duodenum & Incidental & 13 & $N / A$ & N/A & Not fit & No & $14, S D$ & $\mathrm{~N} / \mathrm{A}$ \\
\hline 14 & $74, F$ & Stomach & Gl bleed & 40 & Positive & $2 / 50$ & $\begin{array}{l}\text { Lap. wedge } \\
\text { resection }\end{array}$ & No & $9, \mathrm{SD}$ & Low \\
\hline 15 & $57, M$ & Duodenum & Cholangitis & 40 & $\begin{array}{l}\text { Positive } \\
\text { Negative }\end{array}$ & None & Duodenectomy & No & $62, S D$ & Low \\
\hline 16 & $76, M$ & Stomach & GI bleed & 65 & Negative & $2 / 50$ & No & Yes & $7, S D$ & Inter \\
\hline
\end{tabular}

N/A: No histological diagnosis available

*: Metastatic disease

**: locally advanced

\#: Imatinib was commenced 2 years after the operation when patient was found to have recurrence.

SD: static disease at last follow up.

PD: progressive disease at last follow up. 
ciated co-morbidities they were deemed unfit for major resectional surgery. In both the cases endoscopic biopsies were insufficient to give the histological diagnosis, but EUS (endoscopic ultrasound) findings were consistent with the diagnosis of GIST. They were both followed up by yearly EUS examinations.

Patient 16 had significant iscaemic heart disease and could not withstand staging laparoscopy and hence the operation is deferred till cardiac status improves.

\section{Discussion}

This cohort of patients showed a significant variation in presentation and wide range of disease stages at presentation. Most of these patients could be managed effectively with surgery and/or Imatinib using current protocols. Imatinib was used in patients with unresectable or metastatic disease according to the NICE guidelines[13].

Our experience suggests that current guidelines are clear for the management of unresectable and metastatic GIST; however surgeons are faced with management dilemmas in the following situations.

\section{- Small GIST}

Small GISTs are often diagnosed radiologically as an incidental finding (patient 13 in our series). They are labelled as "benign" purely on the basis of their size and radiological appearance. These tumours, particularly those located in the oesophagus or the duodenum, are difficult to biopsy and in the absence of histological diagnosis there is a potential risk of keeping a malignant GIST under observation or exposing benign GIST to unnecessary surgery. This unnecessary surgery could mean a pancreaticoduodenectomy in such a patient or an oesophagectomy in patient 9, if deemed fit for operation. Currently there is no guidance available on the rationale of regular follow up or of the use of Imatinib in these patients. There are few reported series of endoscopic enucleation of these tumours $[14,15]$. However this is not a widely accepted practice due to lack of robust evidence.

Many patients with a small GIST and requiring regular follow up do not get reported leading to a lack of data regarding long-term survival. There is a need for a central database of these cases to improve reporting and longterm follow-up.

\section{- Debulking surgery}

At the other end of the spectrum are locally advanced tumours (such as patient 4 in our series). This patient clearly benefited from "debulking" surgery followed by Imatinib. He underwent debulking surgery due to pressure symptoms even in the presence of peritoneal metastasis. This approach, which would have been seen as "unconventional" then, proved to be beneficial to the patient. This supports the current view of using Imatinib with cytoreductive surgery for synchronous metastasis [16]. Currently there are number of reports showing increased recurrence-free and overall survival after surgery for metastatic GIST following TKI therapy [17-19]. However, these reports were largely comprised of patients with recurrent disease after the initial resection of the primary disease, and none specifically focused on the role of primary debulking surgery.

The role of surgery may need redefining in such patients.

\section{- Adjuvant therapy with Imatinib}

There are reports showing benefits of adjuvant Imatinib in GIST of high malignant potential [9]. Current trials (ACOSOG Z9000, ACOSOG Z9001, EORTC and SSG XVIII) are addressing the role of adjuvant Imatinib in different groups of patients. The interim results of ACOSOG Z9001 suggest that Imatinib increases recurrence-free survival when administered following the complete resection of a primary GIST. Our number- 6 patient could have potentially benefited from such therapy. She had an excision of a large tumour found incidentally by the gynaecologists. This proved to be GIST of high malignant potential on histology. Adjuvant treatment was not administered, as she had an R0 resection. She remained disease free for 2 years but subsequently developed peritoneal metastasis, which were then treated with Imatinib. We believe that the treatment of such patients should be more aggressive with the use of adjuvant Imatinib while waiting for the final outcomes of ongoing trials.

\section{- Laparoscopic surgery}

The change in nomenclature from leiomyosarcoma to GIST and the advent of Imatinib has changed the general perception of these tumours to be of benign nature, and there is an increasing trend towards laparoscopic treatment $[20,21]$. It is evident from current literature that R0 resections give the best chance of long term cure to such patients and that tumour spillage along with an R1/R2 resection is associated with an increased incidence of recurrence [22]. We feel that GIST should be treated following the principles of "cancer surgery" and that open resection with adequate margins should be performed unless an R0 resection is achievable laparoscopically.

Due to limited number of patients we have not applied any statistics to the data but tried to highlight the grey areas in the management of these patients.

\section{Conclusion}

We feel that future surgical trials need to be directed towards 
- Long-term follow up of small GIST located in areas that are not readily accesible and diagnosed soley on radiological findings and are presumed to be benign.

- Defining the role of debulking surgery, with or without down staging of disease.

Laparoscopic surgery should be considered only if it is not compromising the principles of cancer surgery.

\section{Competing interests}

The authors declare that they have no competing interests.

\section{Authors' contributions}

Mr Stylianides helped in acquisition of data and preparation of the first draft. Mr Date was responsible for conception of idea, overall preparation and revision of the manuscript. Mr Mughal, Mr Pursnani and Mr Ward were responsible for management of the patient and revising the manuscript critically for important intellectual content. All authors read and approved the final manuscript.

\section{References}

I. Shiu MH, Farr GH, Papachristou DN, Hajdu SI: Myosarcomas of the stomach: natural history, prognostic factors and management. Cancer 1982, 49(I): 177-187.

2. Ng EH, Pollock RE, Munsell MF, Atkinson EN, Romsdahl MM: Prognostic factors influencing survival in gastrointestinal leiomyosarcomas. Implications for surgical management and staging. Ann Surg 1992, 21 5(I):68-77.

3. DeMatteo RP, Lewis J], Leung D, Mudan SS, Woodruff JM, Brennan MF: Two hundred gastrointestinal stromal tumors: recurrence patterns and prognostic factors for survival. Ann Surg 2000, 23 I (I):5I-58.

4. Demetri GD, von Mehren M, Blanke CD, Van den Abbeele AD, Eisenberg B, Roberts PJ, Heinrich MC, Tuveson DA, Singer S, Janicek M, Fletcher JA, Silverman SG, Silberman SL, Capdeville R, Kiese B, Peng B, Dimitrijevic S, Druker BJ, Corless C, Fletcher CD, Joensuu H: Efficacy and safety of imatinib mesylate in advanced gastrointestinal stromal tumors. N Engl J Med 2002, 347(7):472-480.

5. Verweij J, Casali PG, Zalcberg J, LeCesne A, Reichardt P, Blay JY, Issels R, van Oosterom A, Hogendoorn PC, Van Glabbeke M, Bertulli R, Judson I: Progression-free survival in gastrointestinal stromal tumours with high-dose imatinib: randomised trial. Lancet 2004, 364(9440): I I 27-II34.

6. Bauer S, Hartmann JT, de Wit M, Lang H, Grabellus F, Antoch G, Niebel W, Erhard J, Ebeling P, Zeth M, Taeger G, Seeber S, Flasshove $M$, Schutte J: Resection of residual disease in patients with metastatic gastrointestinal stromal tumors responding to treatment with imatinib. Int J Cancer 2005, I I 7(2):3।6-325.

7. Scaife CL, Hunt KK, Patel SR, Benjamin RS, Burgess MA Chen LL, Trent J, Raymond AK, Cormier JN, Pisters PW, Pollock RE, Feig BW: Is there a role for surgery in patients with "unresectable" cKIT+ gastrointestinal stromal tumors treated with imatinib mesylate? Am J Surg 2003, I 86(6):665-669.

8. Samelis GF, Ekmektzoglou KA, Zografos GC: Gastrointestina stromal tumours: clinical overview, surgery and recent advances in imatinib mesylate therapy. Eur J Surg Oncol 2007, 33(8):942-950.

9. Nilsson B, Sjolund K, Kindblom LG, Meis-Kindblom JM, Bumming P, Nilsson $\mathrm{O}$, Andersson J, Ahlman $\mathrm{H}$ : Adjuvant imatinib treatment improves recurrence-free survival in patients with high-risk gastrointestinal stromal tumours (GIST). Br J Cancer 2007, 96(II):1656-1658.

10. Goh BK, Chow PK, Chuah KL, Yap WM, Wong WK: Pathologic, radiologic and $P E T$ scan response of gastrointestinal stromal tumors after neoadjuvant treatment with imatinib mesylate. Eur J Surg Oncol 2006, 32(9):96I-963.

II. Eisenberg BL, Judson I: Surgery and imatinib in the management of GIST: emerging approaches to adjuvant and neoadjuvant therapy. Ann Surg Oncol 2004, I I (5):465-475.

12. Blay JY, Bonvalot S, Casali P, Choi H, Debiec-Richter M, Dei Tos AP, Emile JF, Gronchi A, Hogendoorn PC, Joensuu H, Le Cesne A, McClure J, Maurel J, Nupponen N, Ray-Coquard I, Reichardt P, Sciot R, Stroobants S, van Glabbeke M, van Oosterom A, Demetri GD Consensus meeting for the management of gastrointestinal stromal tumors. Report of the GIST Consensus Conference of 20-2I March 2004, under the auspices of ESMO. Ann Oncol 2005, 16(4):566-578

13. NICE: 2004/86 Imatinib for the treatment of unresectable and/or metatastatic gastro-intestinal stromal tumours. National Institute for Clinical Excellence; 2004

14. Rosch T, Sarbia M, Schumacher B, Deinert K, Frimberger E, Toermer $T$, Stolte M, Neuhaus H: Attempted endoscopic en bloc resection of mucosal and submucosal tumors using insulated-tip knives: a pilot series. Endoscopy 2004, 36(9):788-80I.

15. Katoh T, Itoh Y, Mohri T, Suzuki H: Endoscopic enucleation of gastrointestinal stromal tumors of the stomach: Report of five cases. World I Gastroenterol 2008, I 4( I6):2609-26 I I.

16. Raut CP, Dematteo RP: Prognostic Factors for Primary GIST: Prime Time for Personalized Therapy? Ann Surg Oncol 2008 I5:4-6.

17. Andtbacka RH, Ng CS, Scaife CL, Cormier JN, Hunt KK, Pisters PW, Pollock RE, Benjamin RS, Burgess MA, Chen LL, Trent J, Patel SR, Raymond K, Feig BW: Surgical resection of gastrointestinal stromal tumors after treatment with imatinib. Ann Surg Oncol 2007, I 4(I): I4-24

18. Bonvalot S, Eldweny H, Pechoux CL, Vanel D, Terrier P, Cavalcanti A, Robert C, Lassau N, Cesne AL: Impact of surgery on advanced gastrointestinal stromal tumors (GIST) in the imatinib era. Ann Surg Oncol 2006, I3(I 2):1596-1603.

19. Rutkowski P, Nowecki Z, Nyckowski P, Dziewirski W, Grzesiakowska U, Nasierowska-Guttmejer A, Krawczyk M, Ruka W: Surgical treatment of patients with initially inoperable and/or metastatic gastrointestinal stromal tumors (GIST) during therapy with imatinib mesylate. I Surg Oncol 2006, 93(4):304-3II.

20. Cavaliere D, Vagliasindi A, Mura G, Framarini M, Giorgetti G, Solfrini G, Tauceri F, Padovani F, Milandri C, Dubini A, Ridolfi L, Ricci E, Verdecchia GM: Downstaging of a gastric GIST by neoadjuvant imatinib and endoscopic assisted laparoscopic resection. Eur J Surg Oncol 2007, 33(8): 1044-1046.

21. Choi SM, Kim MC, Jung G], Kim HH, Kwon HC, Choi SR, Jang JS, Jeong JS: Laparoscopic wedge resection for gastric GIST: longterm follow-up results. Eur J Surg Oncol 2007, 33(4):444-447.

22. Rutkowski P, Nowecki ZI, Michej W, Debiec-Rychter M, Wozniak A Limon J, Siedlecki J, Grzesiakowska U, Kakol M, Osuch C, Polkowski M, Gluszek S, Zurawski Z, Ruka W: Risk criteria and prognostic factors for predicting recurrences after resection of primary gastrointestinal stromal tumor. Ann Surg Oncol 2007, 14(7):2018-2027.

Publish with Bio Med Central and every scientist can read your work free of charge

"BioMed Central will be the most significant development for disseminating the results of biomedical research in our lifetime. "

Sir Paul Nurse, Cancer Research UK

Your research papers will be:

- available free of charge to the entire biomedical community

- peer reviewed and published immediately upon acceptance

- cited in PubMed and archived on PubMed Central

- yours - you keep the copyright
BioMedcentral 